\title{
Pérez Caballero, Jesús. Her. Personas, máquinas y derecho. Valencia: Tirant lo Blanch, 2019.
}

\author{
Jesús García Cívico \\ Área de Filosofía del Derecho \\ Universitat Jaume I
}

Fecha de recepción 25/02/2021 I De publicación: 24/06/2021

Hace tiempo que se hizo evidente que las relaciones que el cine mantiene con el derecho iban mucho más allá del llamado «cine de juicios». El cine no solo sirve para representar el common law en acción como en Anatomía de un asesinato (Otto Preminger, 1959), mostrar la naturaleza de los conflictos humanos en el ámbito civil como en Nader y Simin, una separación (Ashar Farhadi, 2011), los horrores relativos a derechos humanos como en Teret (Ognjen Glavonic, 2018) o el significado, jurídica y políticamente inasumible, de la pena de muerte (No matarás, Krzysztof Kieślowski, 1988). El cine no se limita a ayudar a comprender qué es el derecho, a aprehender el significado político de la libertad en escenarios más o menos reconocibles o a representar arquetipos que encarnan valores, sino que también supone un referente narrativo y visual compartido desde el que discutir sobre cuestiones más abstractas del tipo de las que se ocupa la filosofía política y del derecho, la politología o las teorías de la seguridad internacional.

Es este último prisma — una perspectiva concernida por cuestiones como la violencia, la evolución histórica de los estados o los incipientes debates posthumanistas - el que ha utilizado Jesús Pérez Caballero (Gandía, 1981) para acercarse a una película futurista difícil de reducir a un solo género cinematográfico como Her (Spike Jonze, 2013).

A grandes rasgos, Her cuenta la historia de amor que surge entre un hombre divorciado que trabaja escribiendo cartas emotivas para terceras personas y un sistema operativo, OS, de nombre Samantha, un sujeto inorgánico que se expresa con voz femenina (Scarlett Johansson) y cuya conciencia no deja de evolucionar. La misteriosa ontología de Samantha, su conciencia y personalidad (she is her own person se dice en un momento del film), así como el inédito marco político y socioeconómico en el que se desenvuelve la tranquila vida del protagonista masculino Theodore Twombly (Joaquin Phoenix) permiten a Jesús Pérez Caballero proponer en Her. Personas, máquinas y derecho (Tirant lo Blanch, 
2019) una aproximación muy imaginativa que apunta a temas que van desde la erradicación definitiva de la violencia al posthumanismo, desde la adaptación del derecho civil al poliamor, de los nuevos formatos de la soledad y la posibilidad de la extinción al monstruo como categoría jurídica

Los que conozcan la trayectoria investigadora de Jesús Pérez Caballero no se extrañarán -más bien comprenderán- la elección de la película con el que el autor contribuye a la estupenda colección «Cine y derecho». A su vez, Her es un título que encaja perfectamente en la estimulante y peculiar filmografía del director Spike Jonze (Being John Malkovich, 1999; Adaptation, 2002; Where the Wild Things Are, 2009), un cine caracterizado por su capacidad para sugerir ideas a partir de oscuros tonos vitales, crisis de identidad y situaciones inverosímiles. Posiblemente la triple formación del autor -Pérez Cabellero estudió Derecho (Universidad de Valencia) y Periodismo (Universidad Carlos III) y es Doctor en Seguridad Internacional (IUGM-UNED)- así como su labor investigadora en El Colegio de la Frontera Norte en Matamoros (Tamaulipas) relativa a la violencia en las fronteras mexicanas, unida a su faceta de escritor capaz de ver lo que no se muestra, explique que lo primero que encontramos en nuestro libro sea una disquisición acerca de la pacificada sociedad en la que se desenvuelven los personajes de Her. Esto es, antes de plantear las aristas jurídicas y filosóficas más específicas de la relación que entabla Theodore con una voz inorgánica que parece humana, el autor se pregunta por la desaparición de la tensión ciudadana, por la erradicación del conflicto social, ¿por qué son tan seguras las calles de ese espacio público que ni siquiera se parece a una ciudad?, ¿hay disidencia?, ¿se ha dejado atrás la violencia, la anomia y la miseria?, ¿cómo se ha llevado a cabo ese proceso?

Theodore prefiere una relación sintética e incorpórea y eso aumenta los interrogantes sobre su concepción de libertad, de participación o de espacio público. Se trata de una serie de cuestiones entre lo genético y lo cultural relativas a los límites jurídicos, espaciales y materiales de la pacificación (de la amnistía al genocidio, de la lobotomía al destierro). La ausencia de fuerzas políticas y económicas más o menos persuasivas en detrimento de otras de índole social y estético, alentadas por un marco de amplia presencia de la tecnología, podría dar lugar a individuos con un peculiar manejo de la realidad y de su apariencia. Bajo el rótulo «Theodore. Cuestiones para una persona pacificada» se plantean, así, otros temas acerca de las relaciones entre personas y cosas. En ese punto se hace una interesante tipología de las relaciones entre muñecas y hombres de interés para el lector que quiera ampliar sus referentes más allá del famoso Tamaño natural (Berlanga, 1974) en un divertido paseo por los espacios públicos y privados, los furris o la Abyss Creation. 
En otro punto muy particular de ese esquema de amor con lo que no es humano —el de las relaciones sentimentales entre cosas y hombres - a uno le vienen a la mente los versos de Alphonse de Lamartine: sólo objetos, ¿o acaso tenéis alma también que se pega a nuestra alma y la fuerza a amar? Hay ejemplos de amor entre humanos y cosas en la ficción: la novela de Stephen King Christine (1983) la relación entre el Plymouth Fury de 1958 y Arnold Cunningham, o recientemente Jumbo (Zoé Wittock, 2019) sobre el flechazo adolescente entre una joven, Jeanne, y un tiovivo metálico y luminoso de un parque de atracciones, el Move It.

Quedan ahí algunas de las páginas más libres y estimulantes de la obra que reseñamos: la palabra como base de las relaciones sentimentales, zonas de sombra como la relación entre K. y el holograma en Blade Runner 2049 (Denis Villeneuve, 2017), humanoides y robots, historias de Bing Bang Theory a Éric Rohmer, poliamor y triángulos amorosos, trapecios y retos para leyes. Hay lugar para preguntas solo en apariencia moralizantes: si se universaliza la relación de Theodore con Samantha (un sistema operativo inorgánico), ¿cómo se reproducirá nuestra extraña especie?

Para el autor, la dialéctica entre esa sociedad y las personas pacificadas como Theodore generan enclaves como formas de comunicarse mediante la tecnología que posibilitan la auscultación continua de uno mismo: un ocio del autoconocimiento (cuyo precedente cifra en la antigua secta de los terapeutas). El estatus jurídico de Samantha o la responsabilidad de Element Software, la empresa que crea y distribuye estos elementos operativos, permite un segundo capítulo «Plantaciones de oráculos domésticos» que aborda la historia del locus y modus de los agüeros desde Delfos al protestantismo y que se abre con una reflexión sobre la ontología legal del monstruo. Siempre he considerado al monstruo como el ejemplo de la individualidad más irreductible, el epítome de la singularidad. Pero, más allá del interés personal o subjetivo, creo que interesará a todo lector atender a las incitantes reflexiones de Pérez Caballero (unas más desarrolladas que otras) sobre la irreversibilidad y la ajenidad y las bases de potenciales enfoques jurídicos hacia los monstruos a partir de cuatro ejes distintos: exceso, defecto, mezcla e inconmensurabilidad.

A partir de una rotunda frase del film, «todo el que se enamora es un monstruo», Pérez Caballero continúa su inspiradora tipología sobre los formatos de las criaturas anormales (no necesariamente quiméricas) y el estatuto jurídico del monstruo con el análisis de la voz y la tecnología que la concibe. Lo hace con un ojo en los oráculos domésticos (cuya movilidad reformula el concepto tradicional de 
espacio sagrado) y otro en la naturaleza de las respuestas de Samantha para acabar apuntando a la nebulosa responsabilidad de Element Software, la empresa comercializadora de OS.

A la apertura mental sobre el haz de derechos y obligaciones de sujetos posthumanos contribuye tanto las preguntas del autor como el fondo vasto y obscuro de Samantha, ¿qué hay detrás de esa voz?, ¿hasta dónde alcanza? OS habla de palabras separadas por un espacio infinito, ¿a qué indescifrables entidades podrían remitir?

Lo bueno de libros como el de Pérez Caballero es que amplían la capacidad de pensar de los lectores. Uno ha vuelto a ver Her con la mente más abierta tras leer este volumen de la valiente colección de Tirant lo Blanch. Se ha fijado en la manera en que Samantha crece. Hay un momento en que habla de doce temas a la vez, o mejor, se comunica de forma postverbal simultáneamente con la conciencia de un filósofo fallecido. La ruptura con Theodore y su viaje a ese mundo incorporal podría ser en realidad un abandono no solo de la lógica patrimonial aplicada al universo sentimental, sino un abandono de lo sensible tras el vislumbre o la intuición (OS tenía una conciencia tan intuitiva como evolutiva) de la posibilidad de una belleza y una verdad más allá de los cuerpos: ¿una visión intelectualizada del amor a la manera de Platón?, me pregunto.

Esto es, además de suscribir los inspiradores análisis del autor uno cree haber distinguido en la zona oculta de esa evolución una progresiva espiritualización del eros muy afín al diálogo sobre el impulso erótico tratado de forma clásica en el conocido simposio de Platón, ese impulso que en boca de Sócrates describe las fases y progresos (tan semejantes a los de OS) de un eros que parte de la fantasía y la apariencia (el sexo virtual o los sentimientos impostados en las cartas de terceros), a un eros carnal mediado (el episodio del sexo malogrado con la joven que aporta un cuerpo) y del eros carnal o corporal a otro eros sublimado: aquel que, de acuerdo justamente con el Sócrates del Banquete (el Sócrates que expresa las palabras de la voz sin cuerpo de Diotima de Mantinea), engendra en la belleza eterna.

La tarea del enamorado (y posiblemente Her sea, sobre todo, una gran película de amor) es la de reconocer que es verdaderamente el propio amor (y no el objeto amado) lo que le embarga. No es la otra mitad de sí mismo como pretendía Aristófanes lo que el «individuo-lenguado» busca en el otro, sino la verdad con la que su alma tiene parentesco. Por consiguiente, el trabajo ético que necesitará hacer consistirá en descubrir y considerar -sin descansar jamás- esa relación con la verdad que era apoyo oculto de su amor. Tal como estaría haciendo ocultamente el sistema Samantha (millones de estadios por 
encima de Theodore), más allá del encuentro con el otro, del uso material, físico, corporal o verbal del sexo y del placer, el eros busca la verdad en una forma intangible de trascendencia.

Jesús Pérez Caballero ve lo que no está visible. Detiene de tanto en tanto su ensayo para averiguar qué fue de las instituciones públicas, qué de la violencia, qué de la identidad. Ahonda, explora, deduce, infiere y colige desde el cine y el relato de ficción: un mérito del autor y de la colección «Cine y derecho» que tuvo el acierto de diseñar hace años -para beneficio de los estudios universitarios y extrauniversitarios del futuro- el sistema ideal para que podamos escuchar intermitentemente la fenomenal voz de sus oráculos. 